\section{Tropical medicine for the 21st century}

\section{Tropical medicine should be concerned with medical problems endemic to the tropics}

EDrToR,-I found the arguments in Kevin $M$ De Cock and colleagues' article on tropical medicine for the 21 st century confused.' Tropical diseases are alive and well: the issue of the $B M \mathcal{F}$ that contained their article also contained articles on Lassa fever in Nigeria; leprosy and tuberculosis in Ethiopia; and the World Health Organisation's attempts to tackle epidemics of plague, Ebola virus disease, yellow fever, and dengue while omitting arguably more serious outbreaks of diphtheria, visceral leishmaniasis, and cholera. Eight of these infections are indigenous to the tropics and have nothing to do with poverty, although riches might make their control easier.

Much of the confusion in the article comes from the misuse of the term tropical medicine, which the authors seem to equate with "urgent health problems of poor countries." And to say that "the question of the role and future of clinical services in resource poor countries is more relevant than the future of tropical medicine itself" is roughly equivalent to saying that the NHS is more important than cardiology.

One traditional working definition of tropical medicine is "medical problems endemic to the tropics"-that is, problems that occur there uniquely or in a special way and are not found, or are not as important, elsewhere. Thus the discipline embraces many infectious (including sexually transmitted) and non-infectious diseases,

\section{Advice to authors}

We receive more letters than we can publish: we can currently accept only about one third. We prefer short letters that relate to articles published within the past four weeks. Letters received after this deadline stand less chance of acceptance. We also publish some "out of the blue" letters, which usually relate to matters of public policy.

When deciding which letters to publish we favour originality, assertions supported by data or by citation, and a clear prose style. Wit, passion, and personal experience also have their place.

Letters should have fewer than 400 words and no more than five references (including one to the BMJ article to which they relate); references should be in the Vancouver style. We welcome pictures.

Letters should be typed and signed by each author, and each author's current appointment and address should be stated. We encourage you to declare any conflict of interest.

Please enclose a stamped addressed envelope if you would like to know whether your letter has been accepted or rejected.

Letters will be edited and may be shortened. including diseases of nutrition and diseases related to the climate. It embraces epidemiology, public health, and prevention. Poverty, poor education, and population growth impinge on these problems. But these are essentially problems of human biology, humans' parasites and their vectors, and the climate. These are problems that those attempting to eradicate malaria forgot and the vaccine makers are beginning to understand. Let us not forget that in many parts of the tropics humans are still fighting for a place in a wild biological world.

Tobacco, motor vehicle accidents, warfare, and refugees are certainly problems of poor countries, but they are not unique to the tropics. They need addressing, but not by the discipline of tropical medicine.

I share De Cock and colleagues' concern about tropical medicine's struggle for survival as a discipline in Europe: it needs a place in which to lodge. Infectious diseases sounds fine, but in Britain there are no departments of infectious disease that stand comparison with the best in the United States or Australia. But the discipline needs a broader base than infectious diseases. There need to be specialist units in Europe in cancer, surgery, paediatrics, and pathology that will house "tropicalists" and provide a base for work in the tropics. This will become increasingly hard to achieve in the new, cost conscious NHS. We also need research units with a base broader than that which can be supplied by the schools of tropical medicine, as there is in Oxford. The schools, nevertheless, will continue to provide the nucleus for growth.

I do not believe that tropical medicine as properly defined is losing its relevance. It remains a viable and valuable discipline around which other disciplines, which are just as vital in improving health and wellbeing in tropical countries, should assemble themselves. Otherwise all our efforts may fail.

Hospital for Tropical Diseases,

ANTHONY BRYCESON London NW11 OPE

1 De Cock KM, Lucas SB, Mabey D, Parry E. Tropical medicine for the 21st century. BMf 1995;311:860-2. (30 September.)

\section{Tropical medicine should become specialty of "health in developing countries"}

EDrToR,-In their article on the future of tropical medicine Kevin $\mathbf{M}$ De Cock and colleagues point out that Northern perspectives of tropical medicine are rooted in the past, with a heavy emphasis on parasitic and other infectious diseases. ${ }^{1}$ They believe that tropical medicine should now focus on the health problems of poor societies living in areas with a warm climate, where poverty rather than parasitic disease is the dominating influence. They also comment that traditional tropical medicine has ignored the burden of non-infectious disease and mention diseases related to tobacco, maternal mortality, and road accidents as important problems. Rightly, they believe that there should be emphasis on how to provide clinical services in resource poor settings.

Despite these comments they suggest that the discipline of tropical medicine in Europe should be absorbed into infectious diseases. This will help in terms of important health problems such as tuber-
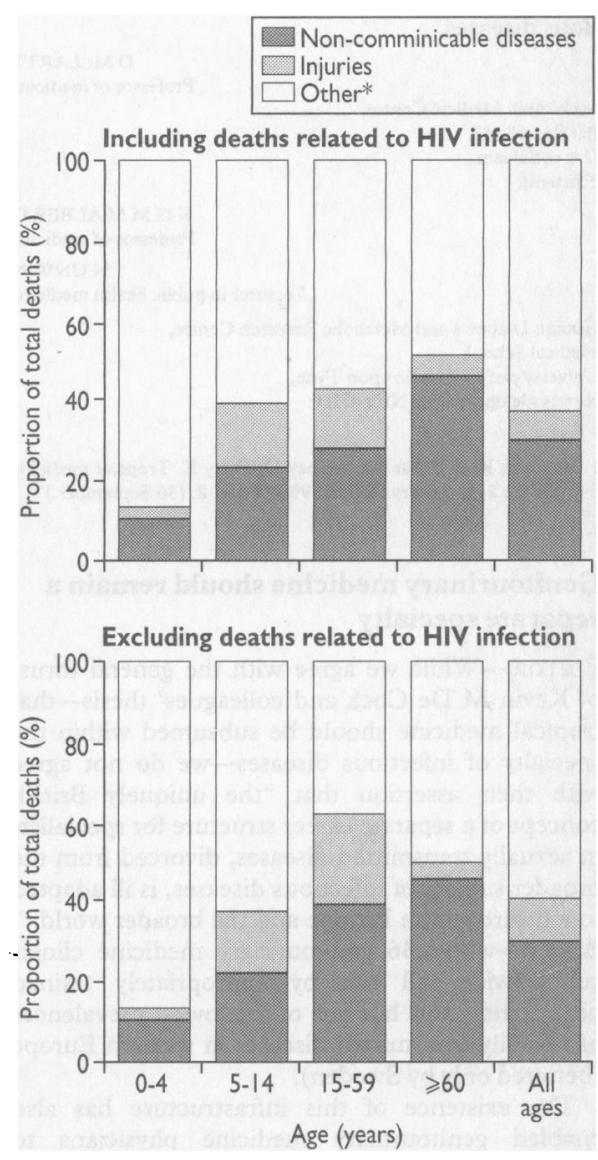

Fig 1-Proportion of deaths attributable to non communicable diseases and injuries in Hai district of Tanzania, 1992-5

* Includesmaternaldeaths ( $<5 \%$ of alldeathsinthose aged 15-59)

culosis, AIDS, and common infectious diseases, which are an increasing burden in developing countries. It does not, however, allow sufficient focus on the increasing burden of non-communicable diseases. These diseases are now reaching epidemic proportions in certain countries, particularly those where there is some economic improvement, such as in South East Asia and Mauritius. Even in sub-Saharan Africa, where the economic state of most countries is static, noncommunicable diseases contribute appreciably to morbidity and mortality.

We have been assessing causes of death in three areas of Tanzania over the past four years. In the northern district of $\mathrm{Hai}$, where economic conditions are slightly better than elsewhere, non-communicable diseases are an important cause of adult death (fig 1). If diseases related to HIV infection are excluded, non-communicable diseases account for $60 \%$ of deaths in adults aged 15 to 59 , with $40 \%$. being due to classic noncommunicable diseases and $20 \%$ to injuries. If deaths due to HIV infection are included then $40 \%$ of deaths are still due to non-communicable diseases.

Thus, even now, non-communicable diseases are a major problem in developing and economic ally impaired countries. Any recommendation for the future of tropical medicine should take this into account. The Overseas Development Admin- 
istration is focusing on this in its "health in the next millennium" work programme, as is the Medical Research Council in its Gambia project, and the Liverpool School of Tropical Medicine now incorporates non-communicable diseases into its diploma courses. We suggest that the specialty of tropical medicine should shift towards a broader specialty of "health in developing countries," with the multidisciplinary inputs that the authors recommend, rather than be subsumed into infectious diseases.

D MCLARTY

Muhimbili Medical Centre, Professor of medicine

PO Box 65243,

Dares

Tanzani

K G M M ALBERTI

Professor of medicin

N UNWIN

Lecturer in public health medicin

Human Diabetes and Metabolic Research Centre,

Medical School,

University of Newcastle upon Tyne,

Newcastle upon Tyne NE2 4HH

1 De Cock KM, Lucas SB, Mabey D, Parry E. Tropical medicin for the 21 st century. $B M 7$ 1995;311:860-2. (30 September.)

\section{Genitourinary medicine should remain a separate specialty}

EDrToR,-While we agree with the general thrus of Kevin M De Cock and colleagues' thesis-that tropical medicine should be subsumed within the specialty of infectious diseases-we do not agree with their assertion that "the uniquely British concept of a separate career structure for specialist in sexually transmitted diseases, divorced from the broader subject of infectious diseases, is ill adapted to a future within Europe and the broader world." Britain-with 236 genitourinary medicine clinics countrywide, all run by appropriately trained physicians-now has one of the lowest prevalences of sexually transmitted diseases in western Europe (bettered only by Sweden)

The existence of this infrastructure has also enabled genitourinary medicine physicians to provide most of the care for people infected with HIV. Departments of genitourinary medicine are well placed to do this, with their policy of open access, strict code of confidentiality, and access to health promotion facilities. The training of genitourinary medicine physicians has been modified to take account of this new area of health provision, but we acknowledge that a broader experience of infectious diseases would be useful.

Many genitourinary medicine clinics now provide additional services for family planning psychosexual counselling (including for erectile dysfunction), and colposcopy-that is, a complete sexual health service. Colleagues overseas, where genitourinary medicine is not a single specialty, envy the benefits of a single discipline; they do not urge us to join with others.

J S BINGHAM

t Thomas's Hospital

Guy's and St Thomas's Hospital Trust,

Guy's and St Tho

De Cock KM, Lucas SB, Mabey D, Parry E. Tropical medicine for the 21st century. $B M{ }^{7} 1995 ; 311: 860-2$. (30 September.)

\section{Clinical care in resource poor countries is often provided by people outside the medical establishment}

EDrTor,-We believe that the second topic in Kevin M De Cock and colleagues' analysis of the future role of tropical medicine in Northern countries-namely, the role and future of clinical services in resource poor countries-needs more debate. ${ }^{1}$ The authors note that the World Bank's World Development Report 1993 reaffirms the importance of good clinical care. ${ }^{2}$ They fail to emphasise that effective provision of the "essential clinical package" involves people outside medicine.

Firstly, in large areas of resource poor countries clinical care is provided by nurses and paramedical workers, who often work independently of physicians. Secondly, good clinical care includes nursing care and effective communication and counselling, especially for chronic diseases and conditions that require substantial behavioural change to prevent their recurrence. Skills to develop communities are also required if services are to have widespread impact. Training in these skills is rarely emphasised in Northern medical institutions. Thirdly, the development of clinical skills is wasted if resources and support systems are lacking or mismanaged. Management information systems are needed to monitor inputs, and surveillance systems are needed to monitor activities and diseases; these systems are usually not regarded as part of "tropical medicine." Fourthly, activities such as family planning and treatment of common childhood diseases, included in the "essential clinical services" package, could be (and often are) performed through channels outside the medical establishment.

Clinical services are, nevertheless, an important component of international health, and the development of a cadre of infectious disease specialists would benefit countries in the North and South alike. As De Cock and colleagues point out, experience in resource poor settings is valuable for clinicians specialising in infectious diseases in Europe; yet Northern institutions regard sending doctors to hospitals in tropical countries as part of overseas aid. Periods in developing countries may more appropriately be regarded as part of a person's training, which should contribute to accreditation but could be paid for in the same way that we expect those from resource poor countries to pay fees for training in the North.

Training in tropical medicine should reflect the changes in clinical priorities highlighted by De Cock and colleagues, emphasise management and communication skills, and give increased emphasis to training and supporting nurses and paramedics. Northern institutions and donors should work with colleagues from resource poor countries to determine how collaborative programmes, based in both the South and the North, can improve the global control of major diseases. Such programmes should recognise the extent to which the North benefits from the experience of the South. FELICITY CUTTS
Senior lecturer in epidemiology ANNE MILLS Professor of health economics and policy

London School of Hygiene and Tropical Medicine,

London WC1E 7HT

1 De Cock KM, Lucas SB, Mabey D, Parry E. Tropical medicine for the 21 st century. $B M M^{7} 1995 ; 311: 860-2$. (30 September.)

2 World Bank. World development report 1993. Investing in health New York: Oxford University Press, 1993.

\section{Videotaping of general practice consultations}

EdrToR,-Jacqueline E Bain and Neil S D Mackay ${ }^{1}$ suggest that the consent rate of $91 \%$ in our study of videotaped consultations in general practice $^{2}$ is evidence of coercion and state that consent rates of $4-10 \%$ are to be expected when coercion is removed. In neither paper that they quote in support of these figures were patients invited to be videotaped. In one study the authors asked patients to speculate how they might feel if so invited. ${ }^{3}$ In the other study patients were given leaflets inviting them to volunteer. ${ }^{4}$ Those patients who did not care one way or the other were included in the $90 \%$ who were claimed to have rejected videotaping. The suggestion that this study produced a consent rate of $10 \%$ is not true: people cannot consent to something unless they have been asked. These points were made in 1987 in response to the original article. ${ }^{56}$

We believe that many patients agree to videotaping out of a sense of altruism and an idea that they may be helping to train better doctors. Clearly, in some circles this could be seen as coercion. Bain and Mackay seem to consider it to be coercive merely to invite a patient to allow his or her consultation to be videoed. There has been a long history in Britain of patients agreeing to contribute to medical education at both undergraduate and postgraduate levels-for example, by being seen by medical students or acting as cases in examinations.

Since coercion in this context is impossible to define or measure we concentrated on outcome measures on the basis that it was important to determine whether videotaping had an adverse effect on the consultation. If $80 \%$ of our sample of patients did feel unhappy about the videotaping it is astonishing that the patients who were videoed reported the same satisfaction as those who were not videoed. Our patients did not produce an "acquiescence response set," as is shown by our results, and our statistics showed that it was extremely unlikely that we had missed a difference in satisfaction between the two groups.

LM CAMPBEL Assistant adviser (assessment) T S MURRAY Regional adviser

West of Scotland Postgraduate Medical

Education Board,

Glasgow G12 9LX

F M SULLIVAN

Senior lecture

Department of General Practice,

University of Glasgow,

Glasgow

1 Bain JE, Mackay NSD. Videotaping of general practice consultations. BMF 1995;311:952. (7 October.)

2 Campbell LM, Sullivan FM, Murray TS. Videotaping of genera practice consultations: effect on patient satisfaction. $B M$ 1995;311:236. (22 July.)

3 Bain JE, Mackay NSD. Patients' assessment of trainee general practitioners. Med Educ 1995;29:91-6.

Servant JB, Mathieson JAB. Video recording in general practice: the patients do mind. $f R$ Coll Gen Pract 1986;36:555-6.

5 Boardman AP, Craig TKJ. Video recording in general practice $f R$ Coll Gen Pract 1987;37:180-1.

6 Mackay HAF. Video recording in general practice. $f R$ Coll Gen Pract 1987;37:181.

\section{Chemotherapy in non-small cell lung cancer}

\section{Large trial will reduce uncertainty}

EDrTOR,-The recent meta-analysis of the role of chemotherapy in non-small cell lung cancer suggests that treatments containing cisplatin improved survival. ${ }^{1}$ The effect of chemotherapy seemed to be consistent across all subgroups (stage of disease, age, sex, performance status, and tumour histology). Because of the heterogeneity of the treatments used in the various trials, however, it was not possible to recommend a particular chemotherapy regimen or to be certain of the size of the benefit. Most importantly, it was not possible to state reliably whether a short course of a widely used cisplatin based treatment would improve survival, or by how much. The economic aspects and quality of life were also not addressed, for obvious reasons.

Considerable doubt therefore remains over the usefulness of combination chemotherapy in non-small cell lung cancer. To answer these questions we have designed a large randomised trial to compare chemotherapy with no chemotherapy in each of the four settings studied in the meta-analysis (surgery, surgery plus radiotherapy, radical radiotherapy, and supportive care). The recommended chemotherapy regimen is three 